\title{
Comparative study of safety and efficacy of Fentanyl and Midazolam combination with Ketamine and Midazolam combination for procedural sedation in pediatric patients
}

\author{
Agarwal $\mathbf{A}^{1}$, Chanchlani $\mathbf{R}^{2}$, Pahelajani $\mathbf{J}^{3}$ \\ ${ }^{1}$ Dr Akansha Agarwal, Assistant Professor, Department of Anesthesia, ${ }^{2}$ Dr Roshan Chanchlani, Associate Professor \\ Department of Surgery, ${ }^{3}$ Dr Jyoti Pahelajani, Senior Resident Department of Anesthesia, Chirayu Medical College and \\ Hospital Bhopal.(M.P).
}

Address for correspondence: Dr Roshan Chanchlani, Email: roshanchanchlani@gmail.com

\begin{abstract}
Introduction: Study was planned to compare the safety and efficacy of Fentanyl and Midazolam combination with Ketamine and Midazolam combination for "procedural sedation" in pediatric patients. Methodology: Sixty ASA1and 2 pediatric patients satisfying inclusion criteria were included in the study. These patients were enrolled by convenience sampling. They were randomized to receive ketamine or midazolam/fentanyl. Both the groups were comparable with respect to age, sex and body weight and proposed procedures. Hemodynamic and respiratory changes occurring during sedation, surgical procedure and during recovery, after administration of the test drug were studied. Measures used for efficacy of drug, that is quantification of distress, pain, anxiety, sedation and complications were also evaluated. Results: On Comparison of age, gender, weight at different time intervals of cases between both groups were comparable with respect to age and weight of patients. On comparison of Pulse Rate at different time intervals of cases between K/M and F/M groups. The mean value of Pulse Rate in $\mathrm{K} / \mathrm{M}$ and $\mathrm{F} / \mathrm{M}$ groups is statistically significant $(\mathrm{p}<0.05)$ only at 5 and 10 minutes after sedation. Comparison of Mean Duration of Procedure and Recovery of cases between K/M and F/M groups shows statistically non-significant difference $(\mathrm{p}<0.05)$ in duration of procedures, and statistically significant difference $(\mathrm{p}<0.05)$ in duration of recovery. Comparison of complication rate of cases between $\mathrm{K} / \mathrm{M}$ and $\mathrm{F} / \mathrm{M}$ groups is statistically non-significant $(\mathrm{p}<0.05)$. Conclusion: We concluded that both the drugs were safe to use in pediatric patients in the doses used intravenous. Ketamine / Midazolam regimen is more effective than the intravenous Fentanyl / Midazolam regimen for relief of pain and anxiety in children, resulting in lesser distress scores.
\end{abstract}

Key words: Fentanyl, Ketamine, Pediatric Procedural Sedation

\section{Introduction}

Administration of sedation and analgesia is often necessary in pediatric patients, even for minor procedures. The goal of procedural sedation is the safe and effective control of pain, anxiety and motion so as to allow a necessary procedure to be performed, and to provide an appropriate degree of memory loss or decreased awareness. When procedures are performed on children who are crying and struggling, they lead to unwanted stress in the child and family, along with adverse procedure outcomes. An important aspect of procedural sedation is analgesia. Pain, perhaps the most feared symptom of a disease, is defined as "an unpleasant sensory and emotional experience associated

Manuscript received: $16^{\text {th }}$ June 2015

Reviewed: $24^{\text {th }}$ June 2015

Author Corrected: $4^{\text {th }}$ July 2015

Accepted for Publication: $20^{\text {th }}$ July 2015 with actual or potential tissue damage or described in terms of such damage". Children had been under treated for the painful procedures because of the wrong notion that they neither suffer or feel pain, nor respond to or remember the painful experiences to the same degree that adult does. But, even the so-called "minor" surgery can also cause significant pain in children, triggering biochemical and physiological stress response. Although sedative and analgesic agents are generally safe, catastrophic complications can occur. Conscious sedation is mostly preferred for procedures that need quick recovery [1]. Midazolam, abenzodiazepine leads to anxiolysis, anterograde amnesia and light hypnosis. It has high amnestic property [2,3]. The incidence of these complications can be reduced with improved understanding of pharmacology of these medications, 
by providing adequate monitoring to sedated patients, by recognizing patients who are at increased risk of experiencing an adverse drug reaction, and by early and appropriate management of complication.

\section{Material and Method}

The study was conducted in a tertiary care institute from March 2012 to March 2015 following the approval of the institutional ethics committee. This comparative study was conducted between equipotent doses of Ketamine and Fentanyl in combination with Midazolam, involving 60 patients satisfying inclusion criteria. Both the groups were comparable with respect to age, sex and body weight and proposed procedures. 60 patients were randomly divided into two groups of 30 each. Both groups received Midazolam 0.1 to 0.3 $\mathrm{mg} / \mathrm{kg}$ i.v. prior to the study drug, until patient's speech slurred or eyes became glassy. Then patients were randomized to receive either Ketamine 0.5 to $2 \mathrm{mg} / \mathrm{kg}$ i.v. or Fentanyl 0.5 to $2 \mathrm{mcg} / \mathrm{kg}$ i.v. until a decreased response to verbal or painful stimuli occurred. Hemodynamic and respiratory changes occurring during sedation, surgical procedure and also during recovery, after administration of the test drug were studied under following parameters: pulse rate, systolic blood pressure, and diastolic blood pressure. Respiratory rate, Oxygen saturation .Measures used for efficacy of drug, that is, quantification of distress, pain, anxiety, sedation were: Visual Analog Scale and Modified Ramsay Sedation Score [4]. Each parameter was studied at different time intervals: Baseline, at the time of sedation, 5 minutes after sedation, 10 minutes after sedation, 15 minutes after sedation, 30 minutes after sedation $1,4,6,12$ hours after sedation, that is recovery period or till the time of discharge.

\section{Results}

Table 1: Comparison of Age and Weight at different time intervals of cases between K/M and F/M

\begin{tabular}{|l|l|l|l|l|l|l|l|}
\hline \multirow{2}{*}{ Variables } & \multicolumn{4}{|l|}{ Group } & \multicolumn{2}{l|}{ Unpaired t-test } \\
\cline { 2 - 7 } & K/M & F/M & \multicolumn{2}{l|}{} \\
\cline { 2 - 7 } & Mean & S.D & Mean & S.D & T value & P value & Difference is \\
\hline AGE(years) & 5.90 & 2.510 & 4.90 & 2.090 & 1.677 & .099 & Not Significant \\
\hline WEIGHT(Kg) & 17.60 & 5.468 & 16.77 & 5.637 & .581 & .563 & Not Significant \\
\hline
\end{tabular}

Both groups were comparable with respect to age and weight of patients

Table 2: Comparison of Gender of cases between K/M and F/M groups

\begin{tabular}{|l|l|l|l|l|l|}
\hline \multicolumn{2}{|c}{} & \multicolumn{2}{|l|}{ Group } & \multirow{2}{*}{ Total } \\
\cline { 4 - 6 } \multicolumn{2}{|c|}{} & K/M & F/M & \\
\hline \multirow{3}{*}{ Gender } & \multirow{3}{*}{ Male } & Count & 24 & 27 & 51 \\
\cline { 3 - 6 } & & $\%$ within GROUP & $80.0 \%$ & $90.0 \%$ & $85.0 \%$ \\
\cline { 3 - 6 } & \multirow{2}{*}{ Female } & Count & 6 & 3 & 9 \\
\cline { 3 - 6 } & & $\%$ within GROUP & $20.0 \%$ & $10.0 \%$ & $15.0 \%$ \\
\hline \multirow{2}{*}{ Total } & Count & 30 & 30 & 60 \\
\cline { 3 - 6 } & $\%$ within GROUP & $100.0 \%$ & $100.0 \%$ & $100.0 \%$ \\
\hline
\end{tabular}

\begin{tabular}{|l|l|l|}
\hline \multicolumn{3}{|l|}{ Chi-Square Tests } \\
\hline & Value & 'p' \\
\hline Pearson Chi-Square & 1.176 & .278 \\
\hline
\end{tabular}

Both groups were comparable with respect to gender of cases $(p<0.05)$. 
Table 3: Comparison of Pulse Rate at different time intervals of cases between K/M and F/M groups

\begin{tabular}{|c|c|c|c|c|c|c|c|}
\hline \multirow[t]{3}{*}{ Pulse Rate/min } & \multicolumn{4}{|l|}{ Group } & \multirow{2}{*}{\multicolumn{2}{|c|}{$\begin{array}{l}\text { Unpaired T- test } \\
\text { applied }\end{array}$}} & \multirow[b]{3}{*}{ Difference is } \\
\hline & \multicolumn{2}{|l|}{$\mathbf{K} / \mathbf{M}$} & \multicolumn{2}{|l|}{ F/M } & & & \\
\hline & Mean & SD & Mean & SD & T-value & P-value & \\
\hline Baseline & 103.93 & 11.073 & 104.53 & 9.031 & -.230 & .819 & Non-Significant \\
\hline At Sedation & 106.27 & 11.765 & 101.87 & 8.709 & 1.646 & .105 & Non-Significant \\
\hline $\begin{array}{l}5 \text { min after } \\
\text { sedation }\end{array}$ & 105.60 & 11.355 & 98.60 & 8.357 & 2.719 & .009 & Significant \\
\hline $\begin{array}{l}\text { 10min after } \\
\text { sedation }\end{array}$ & 105.33 & 10.483 & 98.60 & 8.357 & 2.751 & .008 & Significant \\
\hline $\begin{array}{l}15 \mathrm{~min} \text { after } \\
\text { sedation }\end{array}$ & 101.20 & 8.028 & 98.60 & 8.357 & 1.229 & .224 & Non-Significant \\
\hline $\begin{array}{l}30 \text { min after } \\
\text { sedation }\end{array}$ & 99.07 & 6.963 & 101.87 & 8.709 & -1.375 & .174 & Non-Significant \\
\hline $1 \mathrm{hr}$ after sedation & 99.0333 & 5.86329 & 100.4333 & 8.36117 & -.751 & .456 & Non-Significant \\
\hline $\begin{array}{l}4 \text { hrs after } \\
\text { sedation }\end{array}$ & 97.6000 & 5.36656 & 99.1333 & 8.18212 & -.858 & .394 & Non-Significant \\
\hline $\begin{array}{l}6 \text { hrs after } \\
\text { sedation }\end{array}$ & 96.2000 & 5.64098 & 97.6333 & 6.88067 & -.882 & .381 & Non-Significant \\
\hline $\begin{array}{l}12 \text { hrs after } \\
\text { sedation }\end{array}$ & 94.9333 & 5.84237 & 96.8333 & 6.72660 & -1.168 & .248 & Non-Significant \\
\hline
\end{tabular}

The mean value of Pulse Rate in $\mathrm{K} / \mathrm{M}$ and F/M groups is statistically significant $(\mathrm{p}<0.05)$ only at 5 and 10 minutes after sedation.

Table 4: Comparison of Mean Duration of Procedure and Recovery of cases between K/M and F/M groups

\begin{tabular}{|l|l|l|l|l|l|l|l|}
\hline \multirow{2}{*}{ Variables } & \multicolumn{2}{|l|}{ Group } & \multicolumn{2}{l|}{ Unpaired t-test } \\
\cline { 2 - 8 } & K/M & \multicolumn{2}{l|}{ F/M } & \multicolumn{2}{l|}{} \\
\cline { 2 - 8 } & Mean & S.D & Mean & S.D & T value & P value & Difference is \\
\hline Duration of Procedure (minutes) & 10.93 & 2.741 & 10.67 & 2.218 & .414 & .680 & Not Significant \\
\hline Duration of Recovery (minutes) & 46.83 & 6.757 & 25.83 & 5.427 & 13.271 & .000 & Significant \\
\hline
\end{tabular}

Comparison of Mean Duration of Procedure and Recovery of cases between K/M and F/M groups shows statistically non-significant difference $(p>0.05)$ in duration of procedures, and statistically significant difference $(p<0.05)$ in duration of recovery.

Table 5: Comparison of Complication rate of cases between $\mathrm{K} / \mathrm{M}$ and $\mathrm{F} / \mathrm{M}$ groups

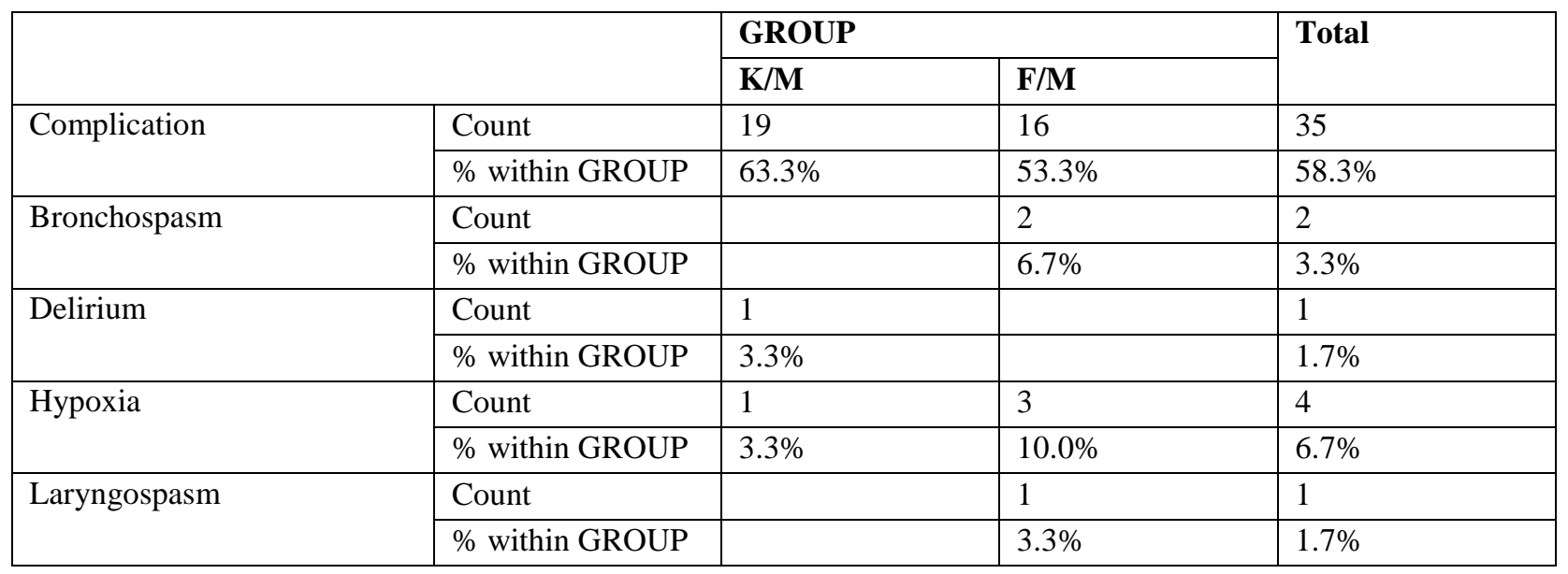




\begin{tabular}{|l|l|l|l|l|}
\hline \multirow{3}{*}{ Oxygen } & Count & 6 & 7 & 13 \\
\cline { 2 - 5 } & $\%$ within GROUP & $20.0 \%$ & $23.3 \%$ & $21.7 \%$ \\
\hline \multirow{3}{*}{ Vomiting } & Count & 3 & 1 & 4 \\
\cline { 2 - 5 } & $\%$ within GROUP & $10.0 \%$ & $3.3 \%$ & $6.7 \%$ \\
\hline \multirow{2}{*}{ Total } & Count & 30 & 30 & 60 \\
\cline { 2 - 5 } & $\%$ within GROUP & $100.0 \%$ & $100.0 \%$ & $100.0 \%$ \\
\hline
\end{tabular}

\begin{tabular}{|l|l|l|}
\hline Chi-Square Test & & \\
\hline & Value & 'p' \\
\hline Pearson Chi-Square & 6.334 & .387 \\
\hline
\end{tabular}

Comparison of Complication rate of cases between $\mathrm{K} / \mathrm{M}$ and $\mathrm{F} / \mathrm{M}$ groups is statistically non-significant $(\mathrm{p}<0.05)$.

\section{Discussion}

Paediatric sedation services are involved in different services including radiology, dentistry, paediatric inpatient services, emergency department and nuclear medicine. Neonates and infants cannot verbalize their pain, they depend on others to recognize, assess and manage their pain only by recognizing their associated behavioral and physiological responses. Studies suggest that pain experienced early in life by term infants many exaggerate effective behavioral response during subsequent painful events. Developments of newer pharmacologic agents and non invasive monitoring techniques have made it possible to administer effective short acting sedatives without compromising patient safety. It is no longer ethical to deprive a child of effective sedatives and analgesics under the often erroneously held belief "a crying child is safer than a sedated child!"Studies have shown that combined use of opiates and benzodiazepines produce a synergistic response but, with significant risk of respiratory depression [5]. Midazolam, a short acting benzodiazepine, has become a very commonly used agent in pediatric procedural sedation. It offers eminent amnesia and anxiolysis but has no analgesic properties. Opioids are often used to achieve adequate level of analgesia for painful procedures, alone or in combination with short-acting sedative like midazolam. Ketamine is a dissociative anesthetic and produces excellent analgesia, amnesia and sedation for painful procedures in children. Propofol has the advantage of rapid onset and offset and very predictable therapeutic effect. However, it lacks analgesic properties and is more suited for painless procedures in radiology suite. The present study was an open randomized comparative trial to compare the efficacy and safety of the two different drugs, Ketamine and Fentanyl, administered intravenously, in dosage of 0.5 to $2 \mathrm{mg} / \mathrm{kg}$ and 0.5 to 2 $\mathrm{mcg} / \mathrm{kg}$, respectively, in combination with Midazolam (
0.1 to $0.3 \mathrm{mg} / \mathrm{kg}$ i.v.), in pediatric patients undergoing 'procedural sedation'. Midazolam was used as an adjunct to both agents to increase amnesia and to decrease anxiety and emergence delirium. Roback MG et al [6] studied adverse events associated with procedural sedation and analgesia in a pediatric emergency department concluded that Procedural sedation with IV midazolam or ketamine or both, or fentanyl and midazolam, appears to be safe. In another study by Robert I. Parker et al [7] they found that the sedative regimen of intravenous midazolam and ketamine was safe and effective. Its use has greatly reduced patient and parent anxiety for diagnostic and therapeutic procedures.

On comparing the mean pulse rate at different time intervals between both the groups, the mean pulse rates at baseline and at the time of sedation were comparable with statistically non-significant difference (p- 0.819). At 5 and 10 minutes post-sedation, the mean pulse rate in $\mathrm{K} / \mathrm{M}$ group increased, but decreased in $\mathrm{F} / \mathrm{M}$ group, showing statistically significant difference (p- 0.009 and 0.008 respectively). At 15 and 30 minutes and 1 hour post-sedation, the mean pulse rate in $\mathrm{K} / \mathrm{M}$ group decreased slightly whereas it slightly increased in $F / M$ group, but the difference was non-significant $(\mathrm{p}<0.05)$. After this the mean pulse rate in both groups kept on decreasing till 12 hours post-sedation, going below baseline values having non-significant ' $p$ ' values. On comparing the mean Systolic Blood Pressure at different time intervals between both the groups, the mean Systolic Blood Pressure at baseline was comparable with statistically non-significant difference (p- 0.564).On comparing the mean Respiratory Rate at different time intervals between both the groups, the mean Respiratory Rate at baseline was comparable with statistically non-significant difference (p- 0.131).From 
the time of sedation till 10 minute post-sedation the difference between both groups was significant $(\mathrm{p}<0.05)$ as mean Respiratory Rate decreased in both groups. After this time, mean Respiratory Rate decreased below baseline value but showing statistically non- significant difference till 12 hours post-sedation(p0.138).On comparing the mean Oxygen Saturation at different time intervals between both the groups, the mean Oxygen Saturation at baseline was comparable with statistically non-significant difference (p- 0.597) as the mean Oxygen Saturation in Ketamine/ Midazolam group was 97.47 with S.D. of $0.900 \%$ and $97.60+$ / $_{-}$ $1.03 \%$ in Fentanyl/ Midazolam group. Mean duration of recovery in Ketamine/ Midazolam group was $46.83+$ /_ 6.75 minutes and in Fentanyl/ Midazolam group was $25.83+/$ _ 5.42 minutes, showing statistically significant difference (p- 0.000), hence it was not comparable. Result is comparable with study done by Robert M. Kennedy et al [8] showing time for induction of sedation was equivalent between groups ( $\mathrm{p}-0.82)$, but recovery was shorter for the F/M group (p-0.02). Sandip A. Godambe, MD, PhD et al[8]found in their study that recovery time with Propofol/Fentanyl is shorter than with Ketamine/Midazolam (33.4 minutes vs. 23.2minutes). The mean baseline Visual Analog Scale in Ketamine/ Midazolam group was 5.77+/_0.97 and in Fentanyl/ Midazolam group was 6.17+/_0.87 Both groups were comparable with statistically nonsignificant difference (p-0.099). this result is comparable with study done by Robert M. Kennedy et al[5] showing that There were no differences between groups $(\mathrm{F} / \mathrm{M}$ vs. $\mathrm{K} / \mathrm{M})$ for mean parental ratings of subjects' usual anxiety $(5.90 \pm 2.70$ vs.5.61 \pm 2.53 ; $\mathrm{P}=.36)$ or ability to handle pain $(6.09 \pm 3.11$ vs. $6.29 \pm 2.58 ; \quad P=.58), \quad$ Sandip A. Godambe, et al[8]found in their study that Propofol/Fentanyl is comparable to Ketamine/Midazolam in reducing procedural distress associated with painful orthopedic procedures in the pediatric emergency department. There was no statistical difference between the groups in the measures of effectiveness. The baseline mean Modified Ramsay Sedation Score was comparable in both groups with 'p' value of 0.613.The mean Modified Ramsay Sedation Score in Ketamine/ Midazolam group was $1.47+/ 0.50$ and in Fentanyl/ Midazolam group it was $1.53+/ 0.50$.

The difference was non-significant at all time intervals between both groups $(\mathrm{p}<0.05)$.The Pearson Chi-Square Test showed statistically non-significant difference in the rate of complications between Ketamine/
Midazolam and Fentanyl/ Midazolam groups (p- 0.387) stating both drugs were comparable with respect to overall complications and can be safely used in pediatric patients. The result in this study is comparable with study done by Robert M. Kennedy et al concluding F/M subjects experienced more hypoxia $(\mathrm{P}=.001)$ and received more breathing cues $(\mathrm{P}=.001)$ and supplemental oxygen $(\mathrm{P}=.04)$ than $\mathrm{did} \mathrm{K} / \mathrm{M}$ subjects. Study conducted by Anthony D. Slonim[9] for pediatric bronchoscopies using ketamine alone or fentanyl with midazolam for procedural sedation showed Complications occurred in 13procedures out of 103 and included oxygen desaturations, stridor, cough, apnea, and nasal bleeding. Twelve of the 13 complications occurred in patients with a diagnosis of HIV infection. Eight of the 13 complications involved children $\$ 3$ years of age. In another study by UrbainIp, MD et al[10]using ketamine alone or with midazolam or fentanyl with midazolam for procedural sedation showed vomiting in $10 \%$ cases and no other complications, thus concluding that Emergency physicians using a structured sedation protocol can safely perform pediatric procedural sedation. In study by Yildizdas Diner et al[11] found that propofol and midazolam-fentanyl produced a higher incidence of respiratory depression and higher mean ETCO[2] during sedation/analgesia than presedation and post sedation/analgesia. Capnography can serve as a useful monitoring tool in the evaluation of ventilation during sedation or sedation/analgesia in clinically stable children. Mark G. Roback, MD et al [12] concluded Ketamine, with or without midazolam, was associated with fewer respiratory adverse events but more vomiting than the commonly used combination of midazolam and fentanyl. The addition of midazolam to ketamine reduced vomiting but also resulted in an increase in respiratory adverse events. Patients with a respiratory adverse event experienced oxygen desaturation $<90 \%$, apnea, or laryngospasm. Thus all these studies were comparable with the results of this study.

\section{Conclusion}

We concluded that both the drugs were safe to use in pediatric patients in the doses used. Intravenous Ketamine / Midazolam regimen is more effective than the intravenous Fentanyl / Midazolam regimen for relief of pain and anxiety in children, resulting in lesser distress scores. Respiratory complications occur less frequently with Ketamine/ Midazolam group than with Fentanyl/ Midazolam, but respiratory support may be needed with either regimen. Both regimens are effective 
for "procedural sedation" in pediatric patients. Average time required for recovery is longer for the Ketamine/ Midazolam combination than for the Fentanyl / Midazolam combination.

\section{Funding: Nil}

\section{Conflict of interest: Nil}

\section{Permission from IRB: Yes}

\section{References}

1. WhitwamJ G, Mc Cloy RF.principles and practice of sedation, $2^{\text {nd }}$ ed Oxford:Blackwell Scientific, 1998:1-54

2. Broennle AM, Cohen DE. Paediatric anesthesia and sedation. Curr Opin Pediatr. 1993 Jun;5(3):310-4.

3. Friedman AG, Mulhern RK, Fairclough D et al. Midazolam premedication for pediatric bone marrow aspiration and lumbar puncture. Med Pediatr Oncol. 1991;19(6):499-504.

4. Ramsay MAE, SavegeTM, Simpson BRJ and Goodwin R. Controlled sedation with alpaxalonealphadolone. Br Med J. 1974 Jun 22;2(5920):656-9.

5. Kennedy RM, Porter FL, Miller JP et al. Comparison of fentanyl/midazolam with ketamine/midazolam for paediatric orthopedic emergencies. Pediatrics. 1998 Oct;102(4 Pt 1):956-63

6. Roback MG, Wathen JE, Bajaj L, Bothner JP. Adverse events associated with procedural sedation and analgesia in a pediatric emergency department: A comparison of common parenteral drugs. Acad Emerg Med. 2005 Jun;12(6):508-13.

7. Parker RI, Mahan RA, Giugliano D, and Parker M M : Efficacy and Safety of Intravenous Midazolam and Ketamine as Sedation for Therapeutic and Diagnostic Procedures in Children.: Pediatrics Vol. 99 No. 3 March 1997, pp. 427-431..

8. Godambe SA, Elliot V, , Matheny D, Pershad J. Comparison of Propofol/Fentanyl Versus Ketamine/Midazolam for Brief Orthopedic Procedural Sedation in a Pediatric Emergency Department. Pediatrics 2003;112(1) July:116-123.

9. Slonim AD, Ognibene FP. Amnestic Agents in Pediatric Bronchoscopy. Chest. 1999 Dec;116(6):18028.

10. Ip U, Saincher A.. Safety of pediatric procedural sedation in a Canadian emergency department. CJEM. 2000 Jan;2(1):15-20..

11. Yldzdaş D, Yapcoglu H, Ylmaz HL. The value of capnography during sedation or sedation/analgesia in pediatric minor procedures. Pediatr Emerg Care. 2004 Mar;20(3):162-5.

12. Roback MG, Wathen JE, Bajaj L, Bothner JP. Adverse Events Associated with Procedural Sedation and Analgesia in a Pediatric Emergency Department: A Comparison of Common Parenteral Drugs. Academic Emergency Medicine Volume 12, Number 6 508-513. DOI: 10.1197/j.aem.2004.12.009.

\section{How to cite this article?}

Agarwal A, Chanchlani R, Pahelajani J. Comparative study of safety and efficacy of Fentanyl and Midazolam combination with Ketamine and Midazolam combination for procedural sedation in pediatric patients. Int J Med Res Rev 2015;3(6):629-634. doi: 10.17511/ijmrr.2015.i6.122. 